\title{
Lengthening of free fibular grafts for reconstruction of the residual leg length discrepancy
}

\author{
Xianghong Zhang ${ }^{1,2}$, Tingting Zhang ${ }^{3}$, Tang Liư ${ }^{*}$, Zhihong Li and Xiangsheng Zhang ${ }^{1}$
}

\begin{abstract}
Background: We evaluated our results of lengthening of free vascularized fibular grafts using a unilateral external fixator in patients with residual leg length discrepancy after free vascularized fibular graft for lower limb reconstruction.

Cases presentation: Two patients were administrated to our hospital with residual tibial length discrepancy after vascularized free fibular graft surgery. Lengthening of the free vascularized fibular graft with a unilateral external fixator was performed to correct the leg length discrepancy. Both patients recovered well with no difficult in activities of daily living at the last follow-up.

Conclusions: This study shows that lengthening of free vascularized fibular grafts with an external fixator is an effective treatment for massive residual leg shortening after vascularized free fibular graft surgery.
\end{abstract}

Keywords: Vascularized free fibular graft, Bone lengthening, Osteomyelitis, Unilateral external fixator

\section{Background}

Massive segmental bone defects often arise from tumor resection, congenital malformation, trauma, osteomyelitis, and so on [1-3]. Though bone micro-vascular transfer has been proven to be an effective technique for reconstruction of larger bone defects [4], the management of larger bone defects remains a considerable surgical challenge [5-7]. Massive structural allografts and vascularized fibular autografts have their own limitations, such as lack of sufficient transplantable materials, donor site morbidity, inflammation, and resorption of the grafts $[8,9]$. Since described by Taylor in 1975 [10], the free vascularized fibular grafts (FVFG) has been widely used for reconstructing a segmental bone defect [11-15]. However, there are few reports on lengthening of FVFG for reconstruction the residual leg length discrepancy (LLD). In this study, we evaluated the results of lengthening of FVFG using a unilateral external fixator $[16,17]$ in 2 patients with residual tibial length discrepancy after FVFG for lower limb reconstruction.

\footnotetext{
* Correspondence: liutang1204@csu.edu.cn

'Department of Orthopedics, The Second Xiangya Hospital of Central South University, 139\# Middle Renmin Road, Changsha, Hunan 410011, People's Republic of China

Full list of author information is available at the end of the article
}

\section{Case presentation}

\section{Case 1}

A 16-year-old female patient was first administrated to our hospital because her right leg was $18 \mathrm{~cm}$ shorter than contralateral side (Fig. 1). When she was 4-year-old, she contracted right tibia pyogenic osteomyelitis, leading to a 6-cm tibial absorption involving the distal epiphysis. The patient had no other past medical history. When she was 5 , the tibia defect was reconstructed by her ipsilateral vascularized fibular graft. However, progressive leg length discrepancy developed with limited range of joint motion (ROM) (Table 1). When she was 16, lengthening of FVFG with a unilateral external fixator was performed to correct the LLD (Fig. 1). We executed an open osteotomy at the level of the middle metaphysis of the matured fibular graft. The patient received preventive intravenous antibiotic (Cefuroxime) for $72 \mathrm{~h}$. The latency period was 7 days after the operation and distraction was performed at a rate of $1.0 \mathrm{~mm}$ per $36 \mathrm{~h}$ in four increments of $0.25 \mathrm{~mm}$, and when the length of bone regeneration had reached approximately $6.0 \mathrm{~cm}$, the distraction rate was reduced to $1.0 \mathrm{~mm}$ every $48 \mathrm{~h}$ [18]. Clinical and radiological examination was carried out every 15 days to assess new bone formation and the pin sites [18]. The rate was adjusted according to the discomfort and swelling of the limb and the quality of 


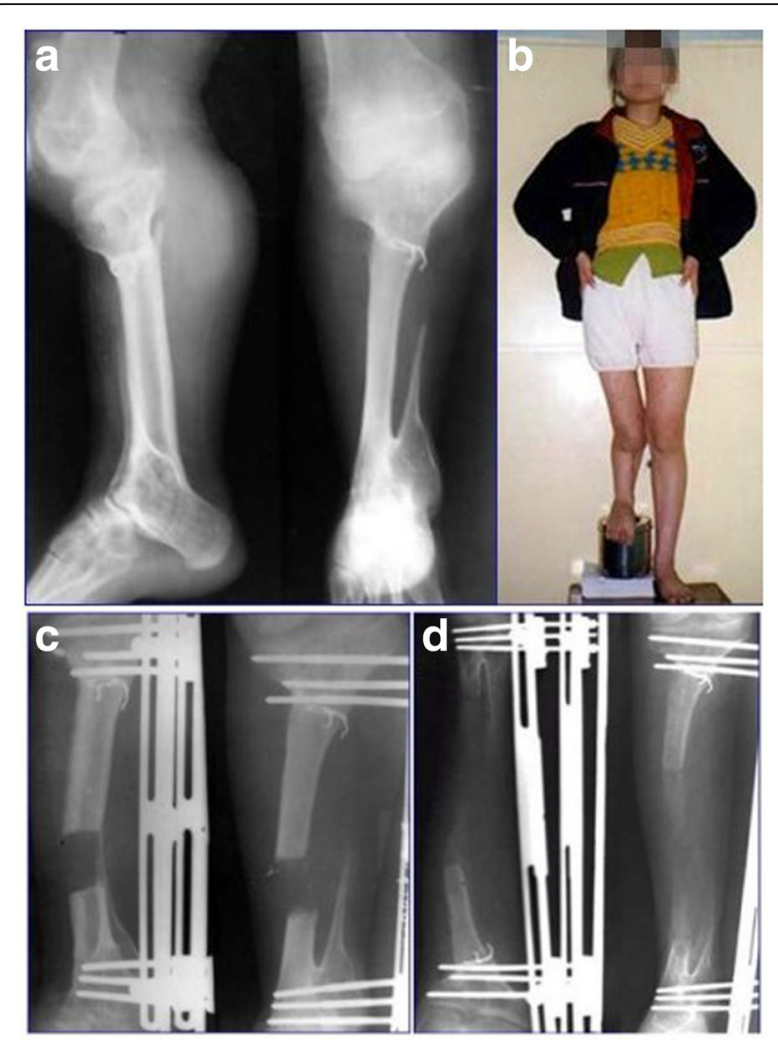

Fig. 1 The $X$-ray film of case 1 reveals reconstruction of the tibia with a FVFG was done (a), she has $18 \mathrm{~cm}$ shortness at the right limb (b), the length correction program with unilateral external fixator was done and the callus regenerated well $(\mathbf{c}, \mathbf{d})$

the regenerate bone like our previous study [18]. Partial weight-bearing was allowed as soon as union of the vascularized fibula graft on either junction was observed on radiographs. We achieved equalization with a unilateral external fixator in 26.5 months. The mean external fixation index was 44.2 day $/ \mathrm{cm}$. She had a pin-track infection and local inflammation, which were managed with pin care and oral antibiotics. The unilateral external fixator was removed when at least three of the four cortices were observed to be united on anteroposterior and lateral radiographs. She was able to walk without walking aids or braces, and to perform almost all activities of daily living with no difficulty based on the recommended criteria [19]. The results were divide into bone results and functional results. Based on the criteria recommended by Paley et al. $[20,21]$, bone result were excellent, and function result were good (Fig. 2, Table 1).

\section{Case 2}

A 17-year-old female patient was administrated to our hospital because her left leg was $9 \mathrm{~cm}$ shorter than contralateral side (Fig. 3 ). When she was 6 years old, she was diagnosed as left tibia pyogenic osteomyelitis. She had no other past medical history. Her upper and almost the middle left tibia were absorbed. She received ipsilateral vascularized fibular graft to reconstruct bone defect at 8-year-old. The distal tibia was fused with fibula. Subsequently, progressive LLD developed. To correct the discrepancy, gradual length correction with a unilateral external fixator was started after being administrated to our hospital (Fig. 3). The lengthening procedure was started at 9 years after fibular graft surgery. A lateral incision was used in the fibula for osteotomy. In order to sustain the anatomic axis, each set of pins was positioned in the same plane and perpendicular to the long axis of the proper lower limb alignment. The patient received preventive intravenous antibiotic (Cefuroxime) for $72 \mathrm{~h}$. The latency period was 7 days after the operation and the rate of distraction was like case 1 according to our previous study [18]. Time to bone union was expressed in every 15 days and it was determined using the follow-up $x$-rays. Physiotherapy, daily nursing care, and regular follow-up were performed together with distraction. We achieved symmetry with a unilateral external fixator in 13.5 months. The mean external fixation index was 45.0 day $/ \mathrm{cm}$. The patient had a relapse clubfoot deformity gait when symmetry was achieved (Table 1). Achilles tendon lengthening surgery was performed to correct the relapse clubfoot deformity (Fig. 4). Partial weight-bearing was allowed as soon as union of the vascularized fibula graft on either junction was observed on radiographs. She can't full weight-bearing until complete union of the vascularized fibula and massive bone allograft to host bone was evident. The results were divide into bone results and functional results. Based on the criteria recommended by Paley et al. [20, 21], bone result and function results were good. (Fig. 4, Table 1).

\section{Discussion and conclusions}

The surgical management of large bone defect is challenging for orthopedic surgeons. Several different treatment options for this complex disease, such as autografts, allografts, induced membranes, microvascular osseous transfer, as well as bone transport [15, 19, 22-24]. Free fibular grafting is considered as one of the standard salvage procedures

Table 1 Range of motion before and after the lengthening surgery

\begin{tabular}{|c|c|c|c|c|}
\hline & \multicolumn{2}{|c|}{ Extension/Flexion of the knee } & \multicolumn{2}{|c|}{ Plantar flexion/dorsiflexion of ankle } \\
\hline & Pre-operation & After the operation & Pre-operation & After the operation \\
\hline Case 1 & $0-0 / 110^{\circ}$ & $0-0 / 95^{\circ}$ & $0-18 / 15^{\circ}$ & $0-13 / 8^{\circ}$ \\
\hline Case 2 & $0-0 / 108^{\circ}$ & $0-0 / 92^{\circ}$ & $0-15 / 10^{\circ}$ & $10-13 /-10^{\circ}$ \\
\hline
\end{tabular}




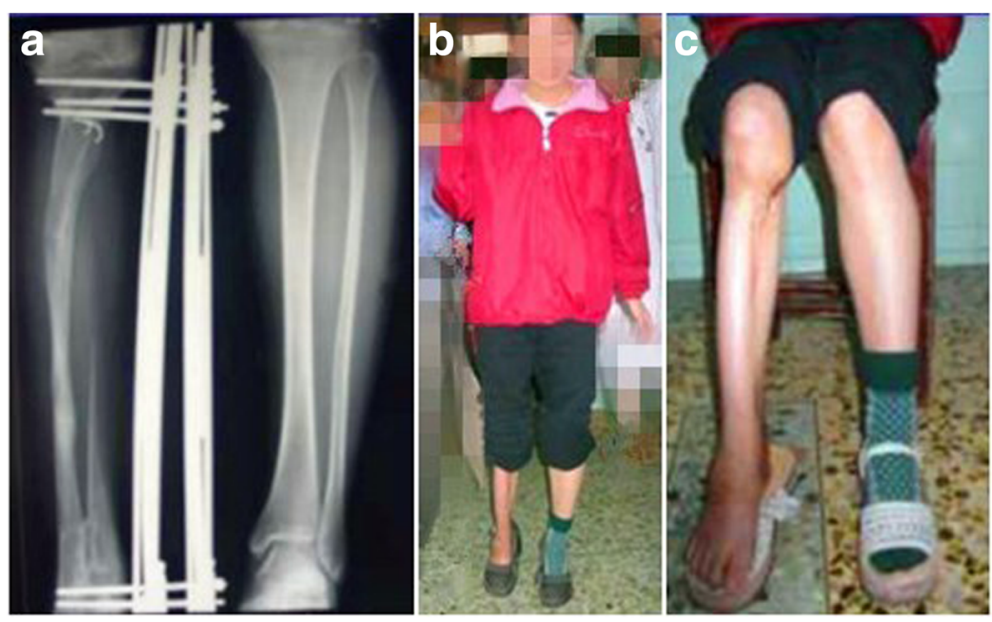

Fig. 2 The X-ray film reveals a total lengthening of $18.0 \mathrm{~cm}$ was achieved (a), and she can walk well without walking aids or braces (b), and the knee and ankle' function were near normal at the last follow-up (c)

for reconstructing segmental skeletal defect [25, 26]. Using free vascularized bone grafts generates better results than using non-vascularized bone grafts [27]. A vascularized osseous transfer has several advantages during the early process of bone repair, including an

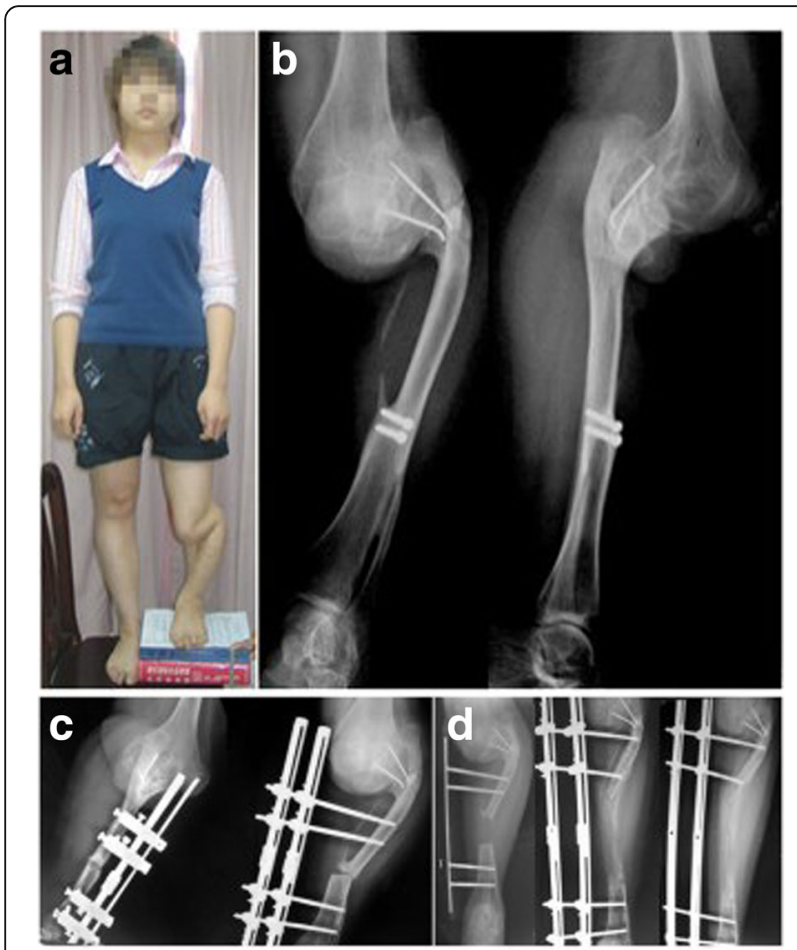

Fig. 3 This clinical image of the case 2 shows $9 \mathrm{~cm}$ shortness at the left $\operatorname{limb}(\mathbf{a})$, and the preoperative X-ray film reveals her upper and most middle left tibia involving the proximal epiphysis were fusioned together with fibula (b), and the length correction program with unilateral external fixator was done and the callus regenerated well $(\mathbf{c}, \mathbf{d})$ enhanced union capacity, the potential for subsequent osseous hypertrophy and greater strength [28].

Though FVFG is a reliable method for bone defect, it is also associated with a high complication rate (Table 2). The most common complications reported were mechanical failure, graft fracture, nonunion, infection, and associated complications at the donor site [29-31]. Although a number of studies have documented the complications that occur during the process of bone repair, little has been reported about the treatment of late complications, such as residual LLD. The complication of residual LLD has not been reported frequently, and a lengthening procedure after FVFG has rarely been reported. There are no guidelines for the lengthening procedure of a FVFG and various types of fixators have been used for bone lengthening. Some authors suggest that fibular graft lengthening using an external fixator is a safe and effective method for correcting LLD [32].

The mechanical performance of vascularized fibular transfer-based lower-limb reconstruction is dependent on the ability of the graft to hypertrophy. FVFG hypertrophy has been well studied. El-Gammal et al. conducted a study on 25 patients with lower limb tumors who underwent reconstruction with vascularized fibula graft, and suggested that hypertrophy of the vascularized fibular graft is a time-related phenomenon and generally affected by the age of the patient [33]. However, the cause of hypertrophy remains unclear. Fibular graft hypertrophy evaluated with standard radiographs is a prerequisite for distraction.

Based on the criteria recommended by Paley et al. $[20,21]$, the results were divided into bone results and functional results. For bone results, four criteria were evaluated: union; infection; deformity and leg-length discrepancy. An excellent bone result was one in which there was union, no infection, deformity $<7^{\circ}$, and leg-length 

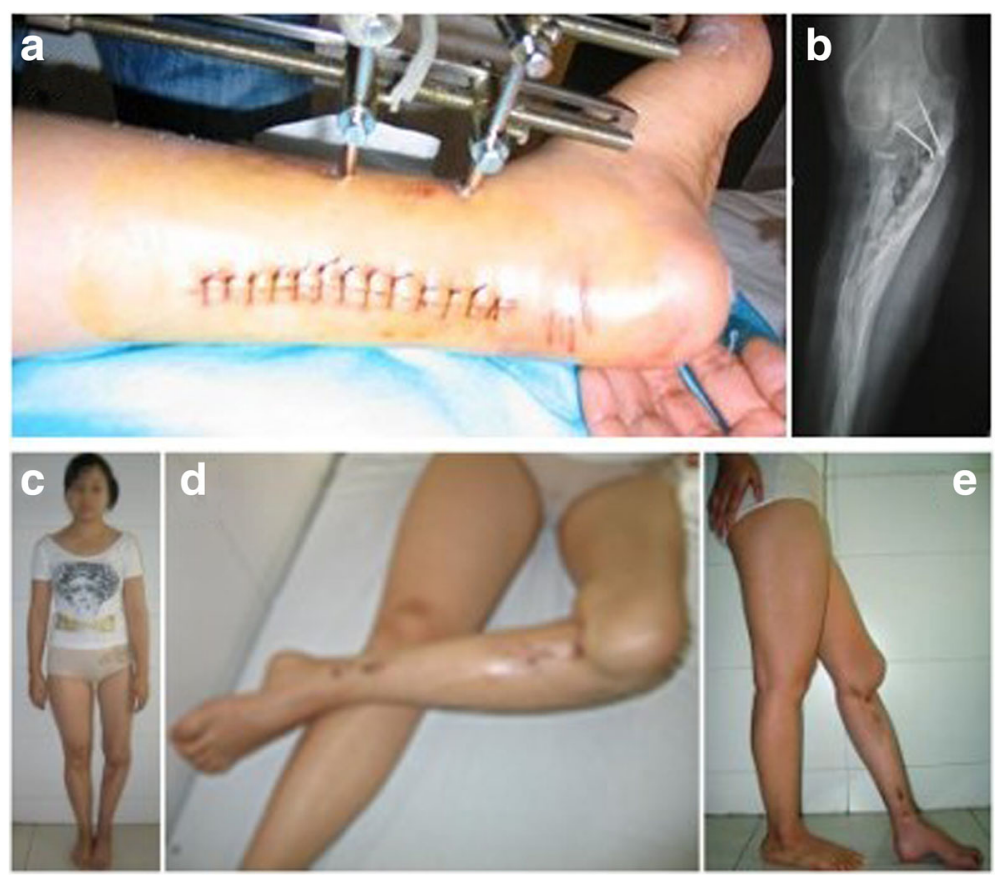

Fig. 4 This image shows a surgery of achilles tendon lengthening was performed to correct the relapse clubfoot deformity (a), and a surgery of bone grafts under the left tibial plateau was performed (b), and she can stand on straightly without walking aids or braces (c, d, e)

discrepancy $<2.5 \mathrm{~cm}$, and an good result was union, plus two of the other criteria. For functional results, five criteria were recommended, including pain; need for walking aids or braces; foot, ankle, or knee deformity or contracture; ankle and/or subtalar loss of range of motion as compared with the preoperative range; and ability to return to normal activities of daily living and/or work. Our two cases could walk well without support at last follow-up. Based on the above criteria, functional results were good due to ankle loss of range of motion as compared with the preoperative range.

The optimal time to perform lengthening on a transferred bone is also a main issue that should be taken into consideration by the orthopedic surgeon (Table 2). De Boer and Wood [34] suggested that 80\% hypertrophy of the FVFG should be observed at the 2-year' follow-up. Courvoisier A et al. reported that three years after the FVFG seems to be a safe delay [32]. In their study, the mean age of their patients at surgery was 12 years, and the mean interval between the end of reconstruction and lengthening was 10 years. Jupiter et al. evaluated the results of skeletal reconstruction performed through a mature, vascularized fibular graft in five patients [28]. In their study, the secondary reconstruction was successful in all five patients, and the average time interval between the original transplant and the secondary reconstruction was 68 months [28]. Ilizarov $\mathrm{S}$ et al. reported a patient with resection of humerus for osteosarcoma, and initial reconstruction of the bone defect with FVFG. Then, the FVFG was subsequent lengthened four years later [12]. They noted that the optimal time for children to do a secondary lengthening was their growth plate closure, so that the lengthening goal is clear. Shaw et al., described a patient with humerus osteosarcoma who underwent limb salvage surgical resection with a vascularized fibula graft followed by limb lengthening [35]. They suggested that the lengthening procedure should be performed once the reconstruction of the extremity with the vascularized fibular autograft is stable. The interval between the end of reconstruction and lengthening in our first patient was 11 years, and this interval in our other patient was 9 years.

There are no guidelines for the lengthening of a FVFG. We adopted the same lengthening protocol as that for native bone [36]. In order to achieve the desired distraction without joint instability, the knee and foot were not included in the frame and daily physiotherapy was required. No matter where you make the osteotomy, the literature [32] showed that bone ingrowth were always succeed (Table 2). The site of osteotomy was performed in the FVFG in our two cases, and bone ingrowth were achieved at last. Ilizarov et al. recommend a rate of distraction of $0.5 \mathrm{~mm}$ per day or less to sustain good formation [12]. However, the rhythm of distraction in our cases was performed at the same rate as that of native bone. No specific complications occurred during the lengthening procedure in our patients and the mean external fixation index also showed no significant differences to the lengthening of other bone distraction with a 


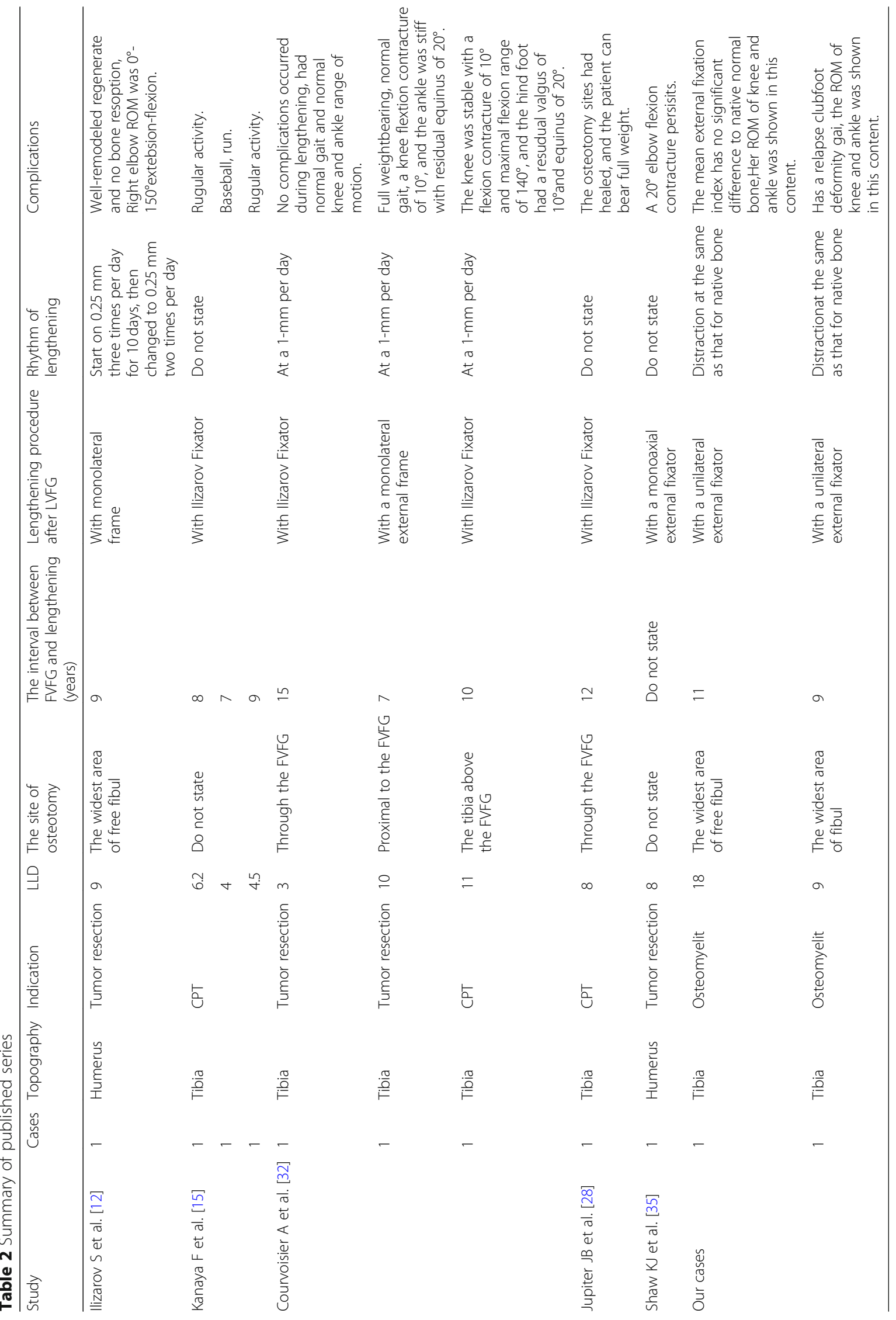


unilateral external fixator. However, it is still difficult to provide formal guidelines for the lengthening procedures after a FVFG due to a lack of cases. Therefore, further studies should be performed and orthopedic surgeons should highlight their key points.

In conclusion, our study shows that lengthening of FVFG with an external fixator is an effective treatment for massive residual leg shortening after vascularized free fibular graft for lower limb reconstruction.

\section{Abbreviations}

FVFG: Free vascularized fibular grafting; LLD: Limb-length discrepancy; ROM: Range of joint motion

\section{Acknowledgements}

We thank all participating patients, as well as the study nurses,co-

investigators, and colleagues who made this trial possible.

\section{Funding}

This work was supported by Natural Science Foundation of Hunan Province, P.R. China(2018JJ2565) and National Natural Science Foundation of China $(81672176,81871783)$. The design of the study and collection, analysis, and interpretation of data were supported by Science Foundation of Hunan Province, P.R. China(2018JJ2565), and the collection, analysis, and writing the manuscript were supported by National Natural Science Foundation of China (81672176, 81871783).

\section{Availability of data and materials}

The datasets used and/or analysed during the current study are available from the corresponding author on reasonable request.

\section{Authors' contributions}

$\mathrm{XHZ}$ wrote the draft of the manuscript and participated in the follow-up examination of the patient and clinical material. TTZ participated in the follow-up examination of the patient and clinical material and helped to draft the manuscript. TL and ZHL performed the surgery, coordinated and helped to draft and finalize the manuscript. XSZ participated in the surgical and medical treatment and execution of the study. All authors read and approved the final manuscript.

\section{Authors' information}

Xianghong Zhang is worked in department of orthopedics,Liuzhou Genera Hospital,Guangxi University of Science and Technology, and he is studying for master's degree at the Second Xiangya Hospital, Central South University.

\section{Ethics approval and consent to participate} Not applicable.

\section{Consent for publication}

The authors obtained the written consent from both patients themselves for the publication of the data and images that appear in the article. A copy of the written consent is available for review by the Editor-in-chief of this journal.

\section{Competing interests}

The authors declare that they have no competing interests.

\section{Publisher's Note}

Springer Nature remains neutral with regard to jurisdictional claims in published maps and institutional affiliations.

\section{Author details}

${ }^{1}$ Department of Orthopedics, The Second Xiangya Hospital of Central South University, 139\# Middle Renmin Road, Changsha, Hunan 410011, People's Republic of China. 'Department of Orthopedics, Liuzhou General Hospital Guangxi University of Science and Technology, Liuzhou 545006, Guangxi, China. ${ }^{3}$ Department of Obstetrics and Gynecology, The Second Xiangya Hospital, Central South University, Changsha 410011, Hunan, China.
Received: 27 July 2018 Accepted: 30 January 2019

Published online: 08 February 2019

\section{References}

1. Hansen ST Jr. Overview of the severely traumatized lower limb: reconstruction versus amputation. Clin Orthop Relat Res. 1989;243:17-9.

2. Liu T, Zhang X, Li Z, Zeng W. Management of chronic radial head dislocation associated with segment bone defect in ulna after osteomyelitis. J Trauma Acute Care Surg. 2012;73(4):1014-7.

3. Liu T, Liu Z, Ling $L$, Zhang $X$. Infection forearm nonunion treated by bone transport after debridement. BMC Musculoskelet Disord. 2013;14:273.

4. Beris AE, Lykissas MG, Korompilias AV, Vekris MD, Mitsionis Gl, Malizos KN, Soucacos PN. Vascularized fibula transfer for lower limb reconstruction. Microsurgery. 2011;31:205-11.

5. Bondurant FJ, Cotler HB, Buckle R, Miller-Crotchett P, Browner BD. The medical and economic impact of severely injured lower extremities. J Trauma. 1998;28:1270-3

6. Mackenzie EJ, Bosse MJ, Castillo RC, Smith DG, Webb LX, Kellam JF, Burgess AR, Swintkowski MF, Sanders RW, Jones AL, Mp MA, Patterson BM, Travison TG, ML MC. Functional outcomes following trauma-related lower-extremity amputation. J Bone Joint Surg Am. 2004;86:1636-45.

7. Williams MO. Long term cost comparison of major limb salvage using Ilizarov method versus amputation. Clin Orthop Relat Res. 1994;301:156-8.

8. Enneking WF, Campanacci DA. Retrieved human allografts: a clinicopathological study. J Bone Joint Surg Am. 2001;83:971-86.

9. El-Negery A, Elmoghazy NA, Abd-Ellatif MS, Elgeidi A. Vascularized fibular medialization for reconstruction of the tibial defects following tumor excision. Int Orthop. 2017;41:2179-87.

10. Taylor Gl, Miller GD, Ham FJ. The free vascularized bone graft: a clinical extension of microvascular techniques. Plast Reconstr Surg. 1975;55:533-44.

11. Malizos KN, Zalavras CG, Soucacos PN, Beris AE, Urbaniak JR. Free vascularized fibular grafts for reconstruction of skeletal defects. J Am Acad Orthop Surg. 2004;12:360-9.

12. Ilizarov S, Blyakher A, Rozbruch SR. Lengthening of a free fibular graft after sarcoma resection of the humerus. Clin Orthop Relat Res. 2007:457:242-6.

13. Javid M, Shahcheraghi GH, Nooraie H. Ilizarov lengthening in centralized fibula. J Pediatr Orthop. 2000;20:160-2.

14. Lim IJ, Kour AK, Pho RW. Lengthening in free vascularized fibular graft. Hand Clin. 1999:15:585-8.

15. Kanaya F, Tsai TM, Harkess J. Vascularized bone grafts for congenital pseudarthrosis of the tibia. Microsurgery. 1996;17:459-69.

16. Liu T, Zhang X, Li Z, Zeng W, Peng D, Sun C. Callus distraction for humeral nonunion with bone loss and limb shortening caused by chronic osteomyelitis. J Bone Joint Surg Br. 2008:90:795-800.

17. Liu T, Zhang X, Li Z, Peng D. Management of Combined Bone Defect and Limb-length Discrepancy after Tibial Chronic Osteomyelitis. Orthopedics. 2011;34:363-7

18. Zhang X, Liu T, Li Z, Peng W. Reconstruction with callus distraction for nonunion with bone loss and leg shortening caused by suppurative osteomyelitis of the femur. J Bone Joint Surg Br. 2007:89:1509-14.

19. Lovisetti G, Agus MA, Pace F, Capitani D, Sala F. Management of distal tibial intra-articular fractures with circular external fixation. Stratefies Trauma Limb Reconstr. 2009:4:1-6.

20. Paley D, Catagni MA, Argnani F, Villa A, Benedetti GB, Cattaneo R. llizarov treatment of tibial nonunions with bone loss. Clin Orthop Relat Res. 1989; 241:146-65

21. Paley D, Maar DC. Ilizarov bone transport treatment for tibial defects. J Orthop Trauma. 2000;14:76-85.

22. El-Gammal TA, El-Sayed A, Kotb MM. Telescoping vascularized fibular graft: a new method for treatment of congenital tibial pseudarthrosis with severe shortening. J Pediatr Orthop B. 2004;13:48-56.

23. Moran SL, Shin AY, Bishop AT. The use of massive bone allograft with intramedullary free fibular flap for limb salvage in a pediatric and adolescent population. Plast Reconstr Surg. 2006;118:413-9.

24. Manfrini M, Bindiganavile S, Say F, Colangeli M, Campanacci L, Depaolis M, Ceruso M, Donati D. Is there benefit to free over pedicled vascularized grafts in augmenting tibial intercalary allograft constructs? Clin Orthop Relat Res. 2017:475:1322-37.

25. Germain MA, Mascard E, Dubousset J, Nguefack M. Free vascularizedfibula and reconstruction of long bones in the child:our evolution. Microsurgery. 2007;27:415-9. 
26. Ghert M, Colterjohn N, Manfrini M. The use of free vascularized fibular grafts in skeletal reconstruction for bone tumors in children. J Am Acad Orthop Surg. 2007;15:577-87.

27. Estrella EP, Wang EH. A comparison of vascularized free fibular flap and nonvascularized fibular graft for reconstruction of long bone defects after tumor resection. J Reconstr Microsurg. 2017;33:194-205.

28. Jupiter JB, Palumbo MA, Nunley JA, Aulicino PL, Herzenberg JE. Secondary reconstruction after vascularized fibular transfer. J Bone Joint Surg Am. 1993; 75:1442-50.

29. Eward WC, Kontogeorgakos V, Levin LS, Brigman BE. Free vascularized fibular graft reconstruction of large skeletal defects after tumor resection. Clin Orthop Relat Res. 2010;468:590-8.

30. Chen CM, Disa JJ, Lee HY, Mehrara BJ, Hu QY, Nathan S, Boland P, Healev J, Cordeiro PG. Reconstruction of extremity long bone defects after sarcoma resection with vascularized fibula flaps: a 10 year review. Plast Reconstr Surg. 2007;119:915-24.

31. Zaretski A, Amir A, Meller I, Leshem D, Kollender Y, Barnea Y, Bickels J, Shpitzer T, Ad-El D, Gur E. Free fibula long bone reconstruction in orthopedic oncology: a surgical algorithm for reconstructive options. Plast Reconstr Surg. 2004;113:1989-2000.

32. Courvoisier A, Sailhan F, Mary P, Damsin JP. Case report: lengthening of a vascularized free fibular graft. Clin Orthop Relat Res. 2009;467:1377-84.

33. El-Gammal TA, El-Sayed A, Kotb MM. Hypertrophy after free vascularized fibular transfer to the lower limb. Microsurgery. 2002;22:367-70.

34. De Boer HH, Wood MB. Bone changes in the vascularised fibular graft. J Bone Joint Surg Br. 1989;71:374-8.

35. Shaw KJ, Crawford AH, Kumar S, Billmire D. Limb lengthening after limb sparing for osteogenic sarcoma of the proximal humerus. Orthopedics. 2001;24:1081-2.

36. Damsin JP, Pous JG, Ghanem I. Therapeutic approach to severe congenital lower limb length discrepancies: surgical treatment versus prosthetic management. J Pediatr Orthop B. 1995;4:164.

Ready to submit your research? Choose BMC and benefit from:

- fast, convenient online submission

- thorough peer review by experienced researchers in your field

- rapid publication on acceptance

- support for research data, including large and complex data types

- gold Open Access which fosters wider collaboration and increased citations

- maximum visibility for your research: over $100 \mathrm{M}$ website views per year

At $\mathrm{BMC}$, research is always in progress.

Learn more biomedcentral.com/submissions 